\title{
USO DO CONCEITO OPORTUNIDADE EM LIVROS NACIONAIS DE EMPREENDEDORISMO À LUZ DA LITERATURA CIENTÍFICA DA ÁREA
}

DOI: 1014211/regepe.v5i2.386

Artigo recebido em: $27 / 06 / 2016$ Artigo aprovado em: 27/06/2016

Fernanda Albanaz - Universidade Positivo - UP' Queila Regina Souza Matitz - Universidade Federal do Paraná - UFPR ${ }^{3}$

Resumo: Este estudo teve como objetivo verificar o uso do conceito de oportunidade em livros de autores brasileiros voltados à disseminação do empreendedorismo, à luz da literatura científica da área. O estudo se justifica, inicialmente, em função da importância de obras dessa natureza na formação da cultura empreendedora nacional, tanto no ambiente acadêmico universitário quanto no ambiente social geral. Além disso, a realização da pesquisa se justifica com base em estudos científicos recentes, com foco no construto oportunidade empreendedora, os quais apontam para a necessidade de investigações do conceito em diferentes contextos culturais e idiomas. A investigação é de natureza qualitativa e exploratória-descritiva. Os dados bibliográficos-textuais foram analisados por meio de análise de conteúdo categorial e temática. Com base nos resultados, observouse um alinhamento entre o uso do conceito nos livros de autores brasileiros com as teorias mais recentes da área, com exceção dos pressupostos a respeito dos efeitos das oportunidades de negócios.

Palavras-chave: Oportunidade; Empreendedorismo; Conceito; Teorias.

\section{USE OF THE CONCEPT OF OPPORTUNITY IN BRAZILIANS BOOKS OF ENTREPRENEURSHIP WITH SUPPORT OF THE SPECIALIZED SCIENTIFIC LITERATURE}

\begin{abstract}
This study aimed to verify the use of the opportunity concept in Brazilians authors books aimed at spreading entrepreneurship, with support of scientific literature. The work is justified, initially, due to the importance of books of this nature in the formation of the national entrepreneurial culture, both in the university academic environment and the general social environment. Additionally, the research

\footnotetext{
1 Artigo proveniente do fast track do IX Egepe. Os autores realizaram as alterações sugeridas pelos avaliadores do evento. queila.matitz@gmail.com
}

2 E-mail: fernandaalbanaz@gmail.com

${ }^{3}$ Endereço: Rua Estados Unidos, 1471, apto. 81, Bacacheri, Curitiba - PR, CEP: 82510-050. E-mail:
\end{abstract}

ALBANAZ, F.; MATITZ, Q. R. S. Uso do conceito oportunidade em livros nacionais de empreendedorismo à luz da literatura científica da área. Revista de Empreendedorismo e Gestão de Pequenas Empresas, v.5, n.2, 2016. 
is justified based on recent scientific studies focusing on the construct entrepreneurial opportunity, which points to the need for investigations of the concept use in different cultural contexts and languages. The research is qualitative and exploratory-descriptive. Bibliographic data were analyzed using categorical and thematic content analysis. Based on the results, it has been observed an alignment between the utilization of the concept in Brazilians authors books with recent theories of the area, except of assumptions about the effects of business opportunities.

Keywords: Opportunity; Entrepreneurship; Concept; Theories.

\section{Introdução}

Pesquisas recentes apontam uma intensificação da atividade empreendedora nas últimas décadas em diversos países. Consequentemente, o estudo e o ensino do empreendedorismo têm recebido atenção crescente (BERNARDES; MARTINELLI, 2004; FLORES; HOELTGEBAUM; SILVEIRA, 2008; SOUZA; SARAIVA, 2010; BLUNDEL; LOCKETT, 2011).

No caso do ensino, especificamente, já se percebe a presença do tema empreendedorismo nos currículos escolares em vários países, o que reflete uma visão da educação como elemento primordial para o desenvolvimento de futuros empreendedores (FLORES; HOELTGEBAUM; SILVEIRA, 2008).

Nas universidades brasileiras, o ensino do empreendedorismo tem sido implantado em escala crescente nos cursos de graduação na última década. Em paralelo, pesquisas e ensino do empreendedorismo na pós-graduação vêm sendo implementados de forma evolutiva no país (CABRAL, 2007; HENRIQUE; CUNHA, 2008). Souza et al. (2004) destacam a importância da disseminação de uma cultura empreendedora nas instituições de Ensino Superior, como forma de propiciar um ambiente empreendedor para futuros profissionais.

Por outro lado, o empreendedorismo é um campo de estudo emergente, não existindo, ainda, teorias abrangentes e consolidadas na área (SOUZA et al., 2004; NASSIF et al., 2010). Essa constatação se configura ao mesmo tempo como uma lacuna e uma oportunidade para pesquisadores interessados no desenvolvimento de

ALBANAZ, F.; MATITZ, Q. R. S. Uso do conceito oportunidade em livros nacionais de empreendedorismo à luz da literatura científica da área. Revista de Empreendedorismo e Gestão de Pequenas Empresas, v.5, n.2, 2016. 
um arcabouço teórico próprio da área, incluindo estudos de conceitos centrais do campo.

Short et al. (2010), por exemplo, descrevem o estado da arte dos estudos do conceito de oportunidade no campo do empreendedorismo. Os autores chamam a atenção para a centralidade do conceito nessa área de estudo e para a formação recente de uma massa crítica de literatura acadêmica centrada no tema. Dentre as propostas de ampliação desses estudos, os autores apresentam algumas áreas das ciências sociais potencialmente férteis para a realização de pesquisas científicas. Destacam, por exemplo, a necessidade de abordagens cross-disciplinary entre o campo do empreendedorismo e as áreas de comportamento organizacional, gestão de recursos humanos, antropologia, gestão de operações, ciências políticas, sociologia, finanças, contabilidade, psicologia, economia, entre outras.

Ao se referirem à possibilidade de interdisciplinaridade entre estudos de empreendedorismo e antropologia, defendem a necessidade de estudos com foco nas diferenças culturais e em suas implicações para a natureza das oportunidades e para os contextos que envolvem oportunidades de novos negócios. Entre as reflexões levantadas pelos autores, destaca-se a questão "Como o conceito de oportunidade é concebido em diferentes culturas e diferentes idiomas?" (SHORT et al., 2010).

Portanto, considerando-se as questões delineadas acima, o objetivo deste trabalho é analisar o uso do conceito de oportunidade em livros de autores brasileiros voltados à disseminação do empreendedorismo no país, à luz dos significados atribuídos ao conceito na literatura científica recente da área de empreendedorismo, cujo foco é o estudo do conceito de oportunidade. A escolha de um produto do mercado editorial como objeto de análise se justifica na medida em que esses textos ao mesmo tempo refletem e contribuem para o uso culturalmente aceito e disseminado do conceito de oportunidade no país.

De acordo com Gutierrez (2013), livros de empreendedorismo de natureza comercial são frequentemente utilizados nas referências bibliográficas de cursos superiores brasileiros. Historicamente, as primeiras publicações de autores brasileiros voltadas à disseminação do empreendedorismo surgiram no final dos anos 90 e início dos anos 2000. José Dornelas, por exemplo, lançou seu primeiro 
livro em 2001 e em 2013 já somava 17 publicações sobre o tema. Um de seus livros, "Empreendedorismo - transformando ideias em negócios", vendeu cerca de 200 mil exemplares. Outro autor reconhecido da área, Fernando Dolabela, estreou nas livrarias em 1999 e tem mais de dez livros publicados a respeito do tema empreendedorismo.

A pesquisa também se encontra alinhada a uma preocupação histórica relacionada ao uso dos conceitos nas ciências sociais. Gellner (1986), por exemplo, já apontava que os debates sobre conceitos nas ciências sociais tendem a ser um problema de criação, escolha, desenvolvimento e substituição de termos. De acordo com Matitz e Vizeu (2012), a respeito do uso dos conceitos nas ciências sociais, o aprimoramento na definição conceitual dos fenômenos sociais pode contribuir para que as pesquisas teórico-empíricas na área alcancem níveis superiores de validade e confiabilidade em termos científicos.

No próximo subitem são apresentados subtemas diretamente relacionados à compreensão do conceito de oportunidade no campo recente de estudos do empreendedorismo. Inicialmente, são apresentados apontamentos gerais a respeito do estudo do conceito de oportunidade empreendedora no contexto da literatura científica da área. Em seguida, são apresentados processos e elementos antecedentes, resultantes e moderadores das oportunidades empreendedoras, também de acordo com estudos recentes da área. Na terceira parte do artigo estão descritos os procedimentos metodológicos. Em seguida, são apresentados e discutidos os resultados da investigação. Finalmente, são apresentadas as considerações finais e as recomendações para futuras pesquisas.

\section{O Conceito de Oportunidade no Campo do Empreendedorismo}

O conceito de oportunidade está intrinsecamente relacionado às origens do estudo acadêmico do empreendedorismo. Entre os princípios-chave da Escola Austríaca, por exemplo, incluem-se a impossibilidade de identificação de todas as oportunidades de mercado e a importância das informações sobre as oportunidades para o surgimento de novos empresários. Os trabalhos de alguns de seus principais

ALBANAZ, F.; MATITZ, Q. R. S. Uso do conceito oportunidade em livros nacionais de empreendedorismo à luz da literatura científica da área. Revista de Empreendedorismo e Gestão de Pequenas Empresas, v.5, n.2, 2016. 
representantes - Schumpeter (1949) e Kirzner (1973) - também têm sido determinantes na compreensão do processo de criação de oportunidades. Schumpeter, por exemplo, propôs o processo de "destruição criativa", no qual novas oportunidades são introduzidas no mercado em detrimento daquelas já existentes, enquanto Kirzner propôs a ideia do empreendedor como aquele que cria um novo equilíbrio ao identificar oportunidades.

Short et al. (2010) destacam a noção de oportunidade como conceito central no campo do empreendedorismo. Segundo os autores, embora historicamente o foco da pesquisa sobre empreendedorismo tenha sido predominantemente direcionado às características e ao comportamento de indivíduos empreendedores no contexto da criação de novos negócios, recentemente o fenômeno da oportunidade empreendedora ou empresarial tem recebido atenção crescente dos pesquisadores.

Em extensa revisão bibliográfica a respeito do tema, os autores constataram que, apesar de alguns estudiosos criticarem a pesquisa em empreendedorismo em razão da falta de bases teóricas adequadas, observa-se em torno do construto oportunidade, um crescimento de pesquisas profícuas em termos teóricos, englobando uma multiplicidade de teorias, dentre elas: a teoria da agência, a teoria da estruturação, a teoria da coerência, a teoria da descoberta, a teoria da criação, a aprendizagem organizacional, a pesquisa sobre emoção e a teoria social cognitiva (SHORT et al., 2010).

Em síntese, essas teorias adotam diferentes perspectivas para explicar a natureza e a origem das oportunidades empreendedoras, além dos processos de formação, os resultados e os fatores intervenientes sobre as oportunidades empreendedoras.

Os autores também identificaram uma definição predominante do conceito de oportunidade na área, bastante instrumental e racional em sua orientação. Em geral, considera-se como oportunidade empreendedora uma situação em que novos bens, serviços, matérias-primas, mercados e métodos de organização podem ser introduzidos por meio da formação de novos meios, fins ou relações entre meios e fins (SHORT et al., 2010).

ALBANAZ, F.; MATITZ, Q. R. S. Uso do conceito oportunidade em livros nacionais de empreendedorismo à luz da literatura científica da área. Revista de Empreendedorismo e Gestão de Pequenas Empresas, v.5, n.2, 2016. 
Hunter (2013), a respeito dos aspectos em comum nas diferentes definições de oportunidade empreendedora encontradas na literatura, destaca a visão da oportunidade como uma perspectiva a respeito de um possível estado ambiental futuro ou um potencial ainda não realizado e que pode ou não ser viável. Uma oportunidade empreendedora, nesse contexto, é uma situação na qual há identificação de uma possibilidade favorável em termos de criação de novos produtos e serviços. De forma geral, os conceitos convergem ao relacionar a oportunidade empreendedora com as ideias de inovação ou novidade, perspectiva de futuro e potencial de mudança de uma situação organizacional e/ou de mercado.

Identificam-se na literatura, com frequência, dois pontos de vista dominantes sobre o construto: enquanto o primeiro classifica a oportunidade como algo que existe e deve ser descoberto, o segundo postula que a oportunidade pode ser criada, ou seja, tem origem em ações relacionadas aos processos empresariais.

A esse respeito, Alvarez e Barney (2007) ressaltam a importância dessas duas teorias a respeito da ação empreendedora: a teoria da descoberta e a teoria da criação. De acordo com os autores, há na literatura uma ênfase na teoria da descoberta e em seus pressupostos em detrimento dos pressupostos da teoria da criação e de suas possíveis interações com a teoria da descoberta.

Entretanto, a teoria da criação do empreendedorismo surge como teoria emergente, capaz de gerar explicações contraditórias e complementares àquelas propostas pela teoria da descoberta. E é crescente a opinião de que a introdução de um segundo ponto de vista teórico - em um campo que tem sido predominantemente dominado por um único ponto de vista teórico -, não apenas ajuda a esclarecer os pressupostos da perspectiva dominante e da perspectiva recém-lançada, como também torna possível articular uma teoria mais geral de empreendedorismo.

Além dos processos relacionados à origem e ao desenvolvimento das oportunidades empreendedoras, conforme apontado acima, pesquisas científicas têm sido realizadas com foco na identificação e descrição dos elementos antecedentes, moderadores e consequentes das oportunidades empreendedoras. Busca-se, por meio dessas investigações, compreender fatores potencialmente influentes sobre os processos de formação de oportunidades empreendedoras, além

ALBANAZ, F.; MATITZ, Q. R. S. Uso do conceito oportunidade em livros nacionais de empreendedorismo à luz da literatura científica da área. Revista de Empreendedorismo e Gestão de Pequenas Empresas, v.5, n.2, 2016. 
das consequências desses processos sobre outras variáveis de nível individual, grupal, organizacional e ambiental.

A Figura 1 a seguir demonstra graficamente as principais relações teóricas que se estabelecem no estudo do conceito de oportunidade no campo do empreendedorismo.

FIGURA 1 - REPRESENTAÇÃO GRÁFICA DAS RELAÇÕES TEÓRICAS PROPOSTAS NA LITERATURA CIENTÍFICA RECENTE DE ESTUDO DO CONCEITO OPORTUNIDADE EMPREENDEDORA

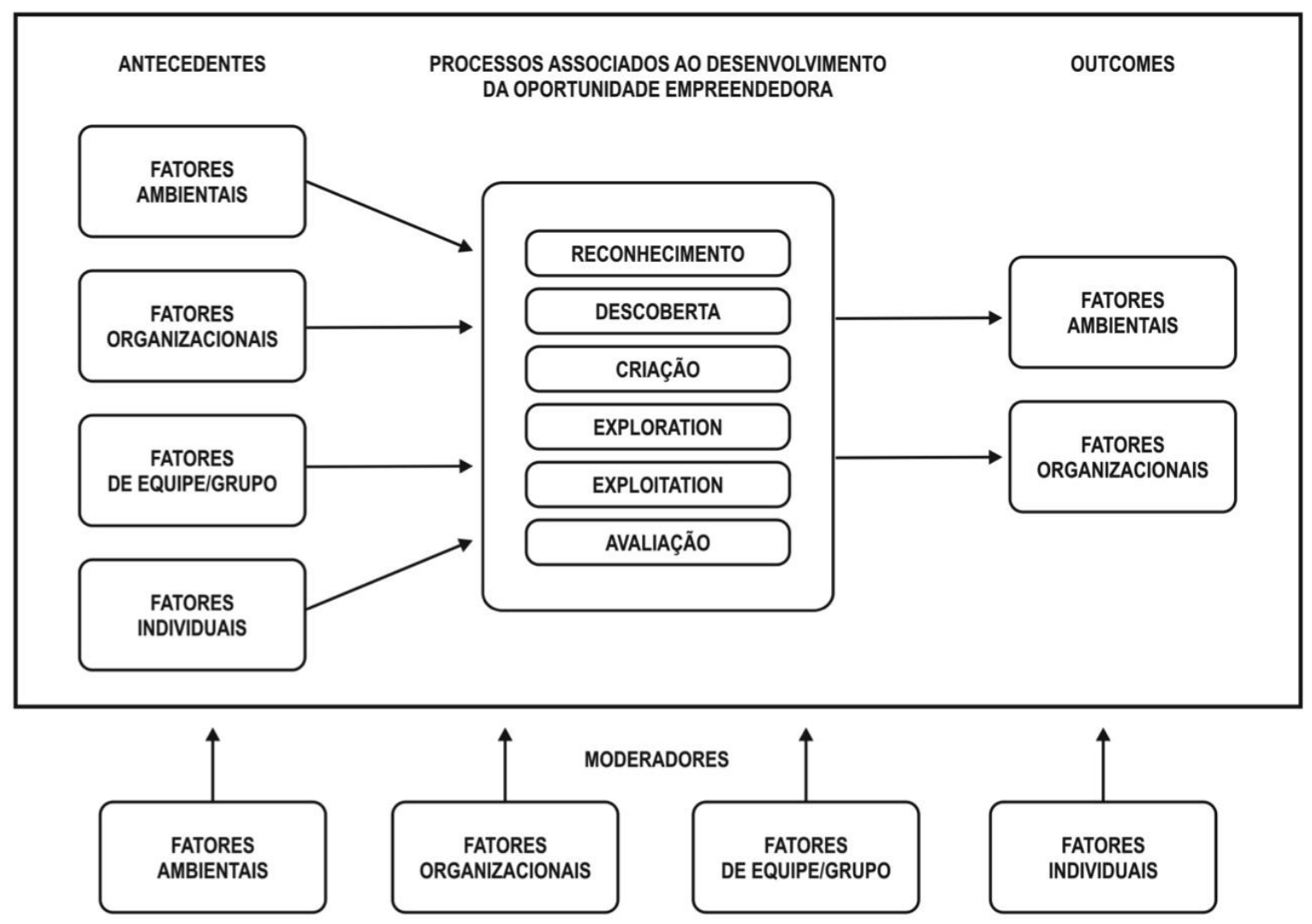

FONTE: os autores (2016).

\section{Processos Relacionados ao Desenvolvimento de Oportunidades no Campo do Empreendedorismo}

O aumento do interesse científico a respeito das oportunidades empreendedoras tem sido acompanhado por um interesse crescente relacionado aos diversos processos associados ao seu desenvolvimento e que podem servir como base para a futura construção de teorias na área, dentre esses: 
reconhecimento, descoberta, criação, exploration, exploitation e avaliação de oportunidades (ARDICHVILI; CARDOZO; RAYC, 2003; SCHINDEHUTTE; MORRIS, 2009).

Segundo Ardichvili, Cardozo e Rayc (2003), o reconhecimento de oportunidades corresponde à etapa inicial do processo de desenvolvimento de oportunidades empreendedoras e diz respeito à identificação de: (i) necessidades ou desejos de mercado; ou (ii) recursos subutilizados. Nessa fase, portanto, ainda não há reconhecimento do ajuste (fit) entre as necessidades e os recursos: "Inventores, cientistas ou indivíduos podem gerar ideias para novos produtos e serviços sem levar em conta a aceitação do mercado ou a viabilidade comercial de invenções ou novas tecnologias" (ARDICHVILI; CARDOZO; RAYC, 2003, p. 110).

A descoberta de oportunidades é uma etapa intermediária do processo de desenvolvimento da oportunidade empreendedora e diz respeito ao reconhecimento da possibilidade de melhor aproveitamento de determinados recursos, considerados subutilizados, em direção a um novo "ajuste" (fit) com necessidades ou desejos de mercado. Nesse caso, portanto, a descoberta diz respeito a uma percepção de que os recursos podem ser realocados para a produção de outros produtos ou serviços capazes de gerar maior valor de mercado:

De acordo com esta perspectiva, os empresários decidem iniciar um novo negócio ou expandir em um novo mercado de produtos quando acham que há oportunidade para redistribuir os recursos atuais, subutilizados, para oportunidades mais promissoras. (ARDICHVILI; CARDOZO; RAYC, 2003, p.110).

Quanto ao processo de criação de oportunidades, corresponde à etapa final do processo de desenvolvimento da oportunidade empreendedora e diz respeito à implantação de um novo "ajuste" (fit) entre necessidades ou desejos de mercado e recursos anteriormente desconectados, sob a forma de um novo negócio: "Criação de conceito [de negócio] envolve redirecionamento e recombinação de recursos a fim de criar e entregar valor superior àquele atualmente disponível" (ARDICHVILI; CARDOZO; RAYC, 2003, p.111).

A respeito dos processos de exploration e exploitation, Schindehutte e Morris (2009) diferenciam o empreendedorismo de descoberta da oportunidade

ALBANAZ, F.; MATITZ, Q. R. S. Uso do conceito oportunidade em livros nacionais de empreendedorismo à luz da literatura científica da área. Revista de Empreendedorismo e Gestão de Pequenas Empresas, v.5, n.2, 2016. 
(exploration) do empreendedorismo de exploração da oportunidade (exploitation). Os autores distinguem, portanto, as atividades do estágio de "busca" e de "desenvolvimento" da oportunidade, uma vez que para cada uma dessas fases, a unidade de análise, as variáveis relevantes, os processos e os resultados são diferentes. A gestão dessa dualidade depende da exploração criativa da tensão que captura os dois extremos, aproveitando, assim, o pluralismo inerente ao processo.

Finalmente, a respeito do processo de avaliação de oportunidades, Ardichvili, Cardozo e Rayc (2003) observam que oportunidades de novos negócios são avaliadas em todas as fases de seu desenvolvimento, mesmo que de forma desarticulada. Por exemplo, a avaliação dos recursos e dos mercados muitas vezes leva a revisões úteis de conceitos de negócio. Ao mesmo tempo, a avaliação de procedimentos tem o efeito de abortar muitas oportunidades. Os autores explicam, ainda, como as avaliações podem estar relacionadas às necessidades ou desejos de mercado ou aos recursos presumivelmente necessários para o desenvolvimento de novos negócios.

Quanto ao termo "avaliação", uma interpretação possível está relacionada a um tipo de julgamento, capaz de determinar se uma oportunidade em desenvolvimento receberá os recursos para amadurecer e passar para a fase seguinte. Um segundo tipo de avaliação é aquela que ajuda a redirecionar o processo de desenvolvimento da oportunidade de modo que tenha maior probabilidade de sucesso.

\section{Elementos Antecedentes ao Surgimento e ao Desenvolvimento de Oportunidades Empreendedoras}

O estudo dos elementos antecedentes às oportunidades empreendedoras busca identificar variáveis ou processos considerados "condutores" do surgimento de novos negócios. Nesse campo de pesquisas busca-se revelar como diferentes níveis de análise - individual, de equipe, organizacional, ambiental, etc. - estão envolvidos nos processos de surgimento e desenvolvimento de oportunidades empreendedoras (ARDICHVILI; CARDOZO; RAYC, 2003; DIMOV, 2007; SHORT et al., 2010).

ALBANAZ, F.; MATITZ, Q. R. S. Uso do conceito oportunidade em livros nacionais de empreendedorismo à luz da literatura científica da área. Revista de Empreendedorismo e Gestão de Pequenas Empresas, v.5, n.2, 2016. 
Em síntese, esses estudos chamam a atenção para a ênfase da área nos aspectos de nível individual e para a necessidade de ampliação do escopo das investigações futuras no sentido de incluir outros níveis de análise (por exemplo, grupal, organizacional, ambiental) em suas pesquisas.

Short et al. (2010) comentam a respeito de esforços consideráveis, por parte de alguns pesquisadores, para entender o processo cognitivo e os processos de aprendizagem associados à criação, descoberta e reconhecimento de oportunidades empreendedoras. Uma série de obras examinou explicitamente o papel dos processos cognitivos e de atributos cognitivos associados ao pensar e ao aprender, elementos que fazem parte do desenvolvimento de oportunidades. Outras contribuições destacam a forma como os insights oriundos de teorias de aprendizado ajudam na compreensão de teorias a respeito do desenvolvimento de oportunidades.

Os autores constataram que os trabalhos anteriores, oriundos de uma variedade de perspectivas teóricas, focaram principalmente em processos de oportunidade no nível individual de análise, enquanto estudos futuros poderiam examinar os processos no nível de equipe, bem como as características organizacionais que servem como antecedentes eficazes na criação, descobrimento e/ou reconhecimento de oportunidades (SHORT et al., 2010).

Também a respeito dos antecedentes da oportunidade empreendedora, Ardichvili, Cardozo e Rayc (2003) consideram como principais fatores influenciadores do processo básico de reconhecimento e desenvolvimento de oportunidades de novos negócios: (1) agilidade empresarial; (2) assimetria de informação e conhecimento prévio; (3) redes sociais; (4) traços de personalidade, incluindo otimismo, autoeficácia e criatividade; e (5) tipo de oportunidade.

Com base nesses fatores, os autores desenvolveram oito proposições: (1) um alto nível de alerta empreendedor é associado ao reconhecimento e desenvolvimento de oportunidades de sucesso; (2) a identificação de oportunidades de sucesso está associada à existência e à utilização de uma rede social ampla formada por quatro elementos: laços fracos, conjunto de ações, parcerias e círculo interno, sendo que a falta de qualquer um desses elementos reduz a probabilidade de sucesso; (3) uma convergência entre os domínios do conhecimento é crítica para 
a identificação de oportunidades de sucesso; (4) o conhecimento prévio dos mercados aumenta a probabilidade de reconhecimento de oportunidades empreendedoras de sucesso; (5) o conhecimento prévio dos problemas dos clientes aumenta a probabilidade de reconhecimento de oportunidades empreendedoras de sucesso; (6) o conhecimento prévio das formas de servir os mercados aumenta a probabilidade de reconhecimento de oportunidades empreendedoras de sucesso; (7) altos níveis de agilidade empresarial estão relacionados a altos níveis de criatividade empresarial e otimismo; e (8) a oportunidade de identificação do processo resulta no enriquecimento da base de conhecimento do empreendedor e no aumento do estado de alerta, levando à identificação de oportunidades de negócios futuros.

Outro estudo a respeito dos antecedentes da oportunidade, desenvolvido por Dimov (2007), destaca a natureza da oportunidade como um produto criativo e ressalta que, em lugar de atribuir as ideias de novos negócios a um indivíduo em particular, deve-se considerar também as influências contextuais e sociais que afetam a geração e a formação de ideias. O autor ressalta não ser realista presumir que os indivíduos desenvolvam suas ideias de forma isolada, mas em contato com outros atores sociais, sendo esse o processo social de elaboração, discussão e interpretação através do qual as ideias iniciais são gradualmente elaboradas, refinadas, alteradas ou mesmo descartadas.

Além disso, de acordo com Dimov (2007), uma das questões centrais do estudo do empreendedorismo - a ser desenvolvida por futuros estudos - é a busca pelo entendimento das razões pelas quais apenas alguns indivíduos reconhecem oportunidades. A respeito do processo criativo presente no empreendedorismo, o autor sugere a necessidade de um aumento da compreensão a respeito dos aspectos criativos do reconhecimento da oportunidade para além da pessoa e do processo envolvido. Em sua opinião, muitos dos relacionamentos identificados requerem maior valorização das situações em que os empresários agem e dos resultados mais imediatos de seus pensamentos e ações.

Em outras palavras, o desenvolvimento da oportunidade deve ser considerado um processo de aprendizagem social na medida em que é necessário considerar também o contexto criativo em que o empreendedorismo ocorre, ou seja,

ALBANAZ, F.; MATITZ, Q. R. S. Uso do conceito oportunidade em livros nacionais de empreendedorismo à luz da literatura científica da área. Revista de Empreendedorismo e Gestão de Pequenas Empresas, v.5, n.2, 2016. 
as influências organizacionais, contextuais e sociais potencialmente intervenientes no processo.

\section{Elementos Resultantes (Outcomes) e Moderadores das Oportunidades Empreendedoras}

O estudo dos elementos resultantes e moderadores das oportunidades empreendedoras busca identificar os efeitos do surgimento de novos negócios e os elementos potencialmente intervenientes nesses efeitos. Busca-se, portanto, verificar e descrever os efeitos do surgimento e desenvolvimento de oportunidades empreendedoras, bem como as variáveis que interferem no tipo e no grau de efeitos do surgimento e desenvolvimento de novos negócios (ALDRICH; CLIFF, 2003; CAROLIS; SAPARITO, 2006; COHEN; WINN, 2007; SHORT et al., 2010; BLUNDEL; LOCKETT, 2011).

Em síntese, esses estudos demonstram a importância das oportunidades empreendedoras como mecanismos de alcance do crescimento e desenvolvimento econômico regionais e nacionais, além da relevância de se considerar a natureza multinível dos fatores moderadores do surgimento, do desenvolvimento e dos efeitos das oportunidades empreendedoras.

Quanto aos efeitos do desenvolvimento de novos negócios, Short et al. (2010) chamam atenção para o fato de que, em grande parte, a importância do conceito de oportunidade se deve aos resultados ou efeitos que derivam do desenvolvimento de uma oportunidade, incluindo a criação de empresas e o crescimento de pequenas empresas. Em geral, considera-se que o grau de inovação da oportunidade empreendedora está positivamente relacionado a um maior potencial de geração de riqueza e crescimento econômico.

Quanto aos elementos moderadores considera-se, em geral, que as ligações entre as oportunidades, seus antecedentes e os resultados são moldadas por processos internos envolvendo indivíduos, bem como processos externos que emanam do grande ambiente social.

Como exemplo, os autores citam a teoria da estruturação desenvolvida por Giddens e a proposição a respeito do entrelaçamento entre as ações dos indivíduos

ALBANAZ, F.; MATITZ, Q. R. S. Uso do conceito oportunidade em livros nacionais de empreendedorismo à luz da literatura científica da área. Revista de Empreendedorismo e Gestão de Pequenas Empresas, v.5, n.2, 2016. 
e estruturas preexistentes sociais. Quando aplicadas à investigação das oportunidades empreendedoras, teorias dessa natureza sugerem a forma como as principais características contextuais desempenham um papel condicionante na determinação da criação, descoberta e/ou exploração de oportunidades. Ao mesmo tempo, perseguir oportunidades remodela o contexto que envolve empresas (SHORT et al., 2010). Uma vasta gama de influências contextuais é citada pelos autores como exemplos de moderadores-chave das oportunidades, tais como o risco, a incerteza, o empreendedorismo estratégico, a natureza do ambiente competitivo, dentre outras.

Cohen e Winn (2007), ilustrativamente, destacam o papel moderador de diferentes tipos de imperfeições de mercado na geração de degradação ambiental, a qual, por sua vez, gera oportunidades significativas para a criação de tecnologias radicais e modelos de negócios inovadores. Para os autores, essas oportunidades estabelecem bases para um modelo emergente de empreendedorismo sustentável.

O estudo de Carolis e Saparito (2006) ilustra outros aspectos potencialmente moderadores das oportunidades empreendedoras, como capital social e fatores pessoais que afetam o comportamento empreendedor. Os autores mencionam, por exemplo, a teoria cognitiva, segundo a qual o comportamento empreendedor é resultado da interação de redes sociais e de vieses cognitivos em empreendedores. Eles propõem que tanto a cognição individual quanto o capital social são importantes para a compreensão do comportamento empreendedor, o que explicaria por que somente algumas pessoas exploram as oportunidades de novos negócios.

Outra relação que tem recebido atenção dos pesquisadores diz respeito à interação entre famílias e empresas. Embora tenham sido muitas vezes tratadas como instituições naturalmente separadas, em seu estudo, Aldrich e Cliff (2003) argumentam que as duas estão intimamente ligadas. Os autores observam que a pesquisa na área do empreendedorismo dá pouca atenção à forma como a dinâmica familiar afeta os processos empresariais fundamentais.

No entanto, as mudanças de longo prazo na composição da família, nos papéis e nas relações de membros da família implicam o surgimento de novas oportunidades de negócios e no reconhecimento de oportunidades, uma vez que muitas empresas - principalmente na fase inicial de desenvolvimento - são 
familiares. Os autores sugerem, portanto, que os estudiosos do empreendedorismo podem se beneficiar de uma perspectiva de inserção da família na criação de novos empreendimentos.

\section{Procedimentos Metodológicos}

Esta pesquisa é uma investigação exploratória-descritiva de natureza qualitativa realizada com base em dados oriundos de comunicação textual formal. Portanto, em lugar de definir população e amostra, foram selecionadas publicações da área do empreendedorismo, conforme os critérios estabelecidos no objetivo geral da pesquisa, para compor o corpus de análise. Em termos formais, incluíram-se livros da área de empreendedorismo escritos por autores brasileiros, em língua portuguesa, e cujo público-alvo é formado prioritariamente por empreendedores e empreendedores em potencial.

As obras selecionadas foram incluídas no corpus com base nos critérios de: (1) atualidade e autoria, sendo incluídos apenas livros publicados a partir de 2010 por editoras brasileiras, de autoria de brasileiros e em língua portuguesa; (2) diversidade; sendo excluídos livros de um mesmo autor; e (3) relevância, sendo incluídos preferencialmente aqueles que já possuíam uma segunda edição ou posterior e que estavam disponíveis para venda em livrarias virtuais ou físicas.

O Quadro 1 apresenta a versão final do corpus da pesquisa.

QUADRO 1 - PUBLICAÇÕES QUE COMPÕEM O CORPUS DA PESQUISA

\begin{tabular}{|l|l|c|l|l|}
\hline \multicolumn{1}{|c|}{ AUTOR(ES) } & \multicolumn{1}{|c|}{ TÍTULO DO LIVRO } & EDIÇÃO & EDITORA & ANO \\
\hline $\begin{array}{l}\text { CHIAVENATO, } \\
\text { Idalberto }\end{array}$ & $\begin{array}{l}\text { Empreendedorismo: dando asas ao } \\
\text { espírito empreendedor }\end{array}$ & $4^{\underline{a}}$ & Manole & 2012 \\
\hline DORNELAS, José & $\begin{array}{l}\text { Empreendedorismo: transformando } \\
\text { ideias em negócios. }\end{array}$ & $4^{\underline{a}}$ & Elsevier & 2012 \\
\hline $\begin{array}{l}\text { MAXIMIANO, } \\
\text { Antonio Cesar } \\
\text { Amaru }\end{array}$ & $\begin{array}{l}\text { Administração para empreendedores: } \\
\text { fundamentos da criação e da gestão de } \\
\text { novos negócios }\end{array}$ & $2^{\underline{a}}$ & $\begin{array}{l}\text { Pearson } \\
\text { Prentice Hall }\end{array}$ & 2011 \\
\hline $\begin{array}{l}\text { TOLOTTI, Marcia; } \\
\text { CAVALCANTI, } \\
\text { Glauco }\end{array}$ & $\begin{array}{l}\text { Empreendedorismo: decolando para o } \\
\text { futuro }\end{array}$ & $1^{\text {a }}$ & $\begin{array}{l}\text { Elsevier/ } \\
\text { SEBRAE }\end{array}$ & 2012 \\
\hline
\end{tabular}

FONTE: Os Autores (2016).

ALBANAZ, F.; MATITZ, Q. R. S. Uso do conceito oportunidade em livros nacionais de empreendedorismo à luz da literatura científica da área. Revista de Empreendedorismo e Gestão de Pequenas Empresas, v.5, n.2, 2016. 
Os textos do corpus foram submetidos a análise de conteúdo categorial e temática (BARDIN, 2011), realizada com base em sentenças, parágrafos e capítulos pertinentes ao objeto de pesquisa. A escolha da unidade textual de análise foi feita caso a caso, com base na possibilidade de enquadramento e interpretação das ocorrências de acordo com as categorias de análise apresentadas a seguir.

- Conceito de oportunidade: Atribuições a respeito da natureza do fenômeno "oportunidade" no campo do empreendedorismo. Buscou-se identificar os significados atribuídos ao termo "oportunidade" em termos de: (i) processos associados ao desenvolvimento da oportunidade; (ii) nível de análise do(s) agente(s) relacionado à origem ou desenvolvimento da oportunidade; (iii) elementos antecedentes, moderadores e consequentes do fenômeno "oportunidade".

(i) Processos associados à origem e/ou ao desenvolvimento da oportunidade

- Percepção: Detecção das necessidades do mercado e/ou dos recursos subempregados. Buscou-se identificar ocorrências do termo oportunidade nos textos que compõem o corpus em que pudesse deduzir que o conceito de oportunidade no contexto analisado está relacionado exclusivamente à detecção ou percepção de necessidades do mercado e/ou de recursos subempregados;

- Descoberta: Reconhecimento de um "ajuste" entre necessidades particulares do mercado e recursos específicos. Buscou-se identificar ocorrências do termo oportunidade nos textos que compõem o corpus desta pesquisa em que pudesse deduzir que o conceito de oportunidade no contexto analisado está relacionado exclusivamente à detecção ou percepção de uma situação potencial de ajuste entre necessidades do mercado e recursos subempregados;

- Criação: Proposta de um novo "ajuste" entre as necessidades e os recursos até então separados na forma de um conceito de negócio. Buscou-se identificar ocorrências do termo oportunidade nos textos que

ALBANAZ, F.; MATITZ, Q. R. S. Uso do conceito oportunidade em livros nacionais de empreendedorismo à luz da literatura científica da área. Revista de Empreendedorismo e Gestão de Pequenas Empresas, v.5, n.2, 2016. 
compõem o corpus em que pudesse deduzir que o conceito de oportunidade no contexto analisado está exclusivamente relacionado à proposta de implementação de um negócio com base em um novo "ajuste" entre necessidades e recursos até então separados;

- Exploration: Busca pela oportunidade e descoberta da oportunidade. Buscou-se identificar ocorrências do termo oportunidade nos textos que compõem o corpus desta pesquisa em que pudesse deduzir que 0 conceito de oportunidade no contexto analisado está relacionado à busca e/ou descoberta de uma oportunidade de novos negócios;

- Exploitation: Exploração de uma oportunidade conhecida em termos de refinamento, eficiência, seleção e implementação. Buscou-se identificar ocorrências do termo oportunidade nos textos que compõem o corpus desta pesquisa em que pudesse deduzir que o conceito de oportunidade no contexto analisado está relacionado ao desenvolvimento de uma oportunidade já reconhecida, criada ou descoberta;

- Avaliação: Exercício de um tipo de julgamento, com o objetivo de determinar se uma oportunidade será desenvolvida ou, se estiver em desenvolvimento, receberá os recursos para amadurecer e passar para a fase seguinte. Buscou-se identificar ocorrências do termo oportunidade nos textos que compõem o corpus em que pudesse deduzir que 0 conceito de oportunidade no contexto analisado está relacionado a algum tipo de avaliação formal ou informal da oportunidade.

(ii) Níveis de análise do(s) agente(s) relacionados à origem ou desenvolvimento da oportunidade empreendedora

- Individual: Quando o agente relacionado à origem ou desenvolvimento da oportunidade é o indivíduo. Buscou-se identificar ocorrências do termo oportunidade nos textos que compõem o corpus em que pudesse deduzir que o indivíduo é o agente responsável pelos processos associados à origem ou desenvolvimento da oportunidade;

ALBANAZ, F.; MATITZ, Q. R. S. Uso do conceito oportunidade em livros nacionais de empreendedorismo à luz da literatura científica da área. Revista de Empreendedorismo e Gestão de Pequenas Empresas, v.5, n.2, 2016. 
- Grupo/Equipe: Quando o agente relacionado à origem ou desenvolvimento da oportunidade é o grupo ou a equipe. Buscou-se identificar ocorrências do termo oportunidade nos textos que compõem o corpus em que pudesse deduzir que o grupo ou a equipe é o agente responsável pelos processos associados à origem ou desenvolvimento da oportunidade.

- Organizacional: Quando o agente relacionado à origem ou desenvolvimento da oportunidade é a organização. Buscou-se identificar ocorrências do termo oportunidade nos textos que compõem o corpus em que pudesse deduzir que a organização é o agente responsável pelos processos associados à origem ou desenvolvimento da oportunidade.

(iii) Elementos antecedentes, moderadores e consequentes do surgimento e desenvolvimento de oportunidades empreendedoras

- Antecedentes: elementos de nível individual, grupal, organizacional ou ambiental associados ao contexto de surgimento e desenvolvimento de oportunidades empreendedoras. Buscou-se identificar ocorrências do termo oportunidade nos textos que compõem o corpus em que é possível deduzir os antecedentes do surgimento e/ou desenvolvimento da oportunidade de novos negócios;

- Moderadores: elementos de nível individual, grupal, organizacional ou ambiental intervenientes no surgimento, desenvolvimento e nos efeitos de oportunidades empreendedoras. Buscou-se identificar ocorrências do termo oportunidade nos textos que compõem o corpus em que é possível deduzir os elementos moderadores do surgimento, do desenvolvimento e dos efeitos da oportunidade de novos negócios;

- Consequentes: elementos individuais, grupais, organizacionais ou ambientais resultantes do surgimento e desenvolvimento de oportunidades empreendedoras. Buscou-se identificar ocorrências do termo oportunidade nos textos que compõem o corpus em que é 
possível deduzir os efeitos do surgimento e/ou desenvolvimento da oportunidade de novos negócios.

\section{Apresentação e Discussão dos Resultados}

A partir da leitura dos livros que fazem parte do corpus desta pesquisa, foram identificadas 330 ocorrências do termo oportunidade, distribuídas por ordem crescente de frequência da seguinte forma: 141 ocorrências em Dornelas (2012), 77 ocorrências em Chiavenato (2012), 59 ocorrências em Tolotti e Cavalcanti (2012) e 53 ocorrências em Maximiano (2011). Das 330 ocorrências encontradas inicialmente, 43 foram descartadas por não estarem semanticamente relacionadas ao contexto do empreendedorismo, resultando em um total de 287 ocorrências utilizadas como objeto da análise de conteúdo categorial.

Quanto aos processos associados à origem e ao desenvolvimento da oportunidade, as ocorrências foram classificadas de acordo com seis subcategorias: percepção, descoberta, criação, exploration, exploitation e avaliação. A etapa de percepção da oportunidade foi identificada em todos os livros, enquanto as de descoberta e criação foram identificadas em três dos quatro livros. A análise também demonstrou que os processos de exploration e exploitation são mencionados por todos os autores. Quanto ao processo de avaliação, também foi identificado em todos os livros do corpus de análise. Observa-se, portanto, abrangência teórica da literatura analisada em termos da apresentação dos processos associados à origem e ao desenvolvimento da oportunidade empreendedora, conforme propostos na literatura científica da área.

Quanto ao agente responsável pelos processos associados à origem ou ao desenvolvimento da oportunidade empreendedora, as ocorrências foram classificadas nas subcategorias: individual, equipe e organizacional. Destas, 226 ocorrências foram classificadas como de nível individual; 51 ocorrências como organizacional; 7 ocorrências foram classificadas como de nível de equipe; 1 ocorrência foi classificada simultaneamente como de nível individual e de equipe; e 2 foram classificadas como "não se aplica". Percebe-se que a maioria das ocorrências

ALBANAZ, F.; MATITZ, Q. R. S. Uso do conceito oportunidade em livros nacionais de empreendedorismo à luz da literatura científica da área. Revista de Empreendedorismo e Gestão de Pequenas Empresas, v.5, n.2, 2016. 
atribui a origem e o desenvolvimento da oportunidade empreendedora ao indivíduo, seguida pelo nível organizacional.

Há, portanto, ênfase na importância do indivíduo empreendedor como agente responsável pelas oportunidades empreendedoras, conforme apontam os trabalhos revisionais recentes da área. Ao mesmo tempo, há comparativamente uma quantidade considerável de atribuições ao nível organizacional. Infere-se, a partir desses dados, que novas oportunidades empreendedoras são originadas e desenvolvidas a partir de negócios já existentes.

A análise dos antecedentes das oportunidades empreendedoras permitiu identificar um total de 129 ocorrências, as quais foram classificadas com base em análise de conteúdo temática. A maioria dos antecedentes apresenta relação direta com o indivíduo empreendedor, envolvendo processos cognitivos, tais como: observação, percepção, conhecimento e criatividade. Em menor número - tanto em quantidade de categorias como em números absolutos - pode-se observar tipos de antecedentes relacionados a elementos do contexto externo ou ambientais, tais como as condições do mercado ou o ambiente geral.

Dentre os antecedentes encontrados nos livros analisados, alguns aparecem com mais frequência. Um deles é o mercado como fonte de oportunidade, com 14\% das ocorrências. O segundo antecedente mais encontrado foi a observação da realidade, com $12 \%$. Nos dois casos, os autores consideraram que a oportunidade é vista como algo que já existe e que, portanto, só precisa ser identificada. Essa identificação pode ser feita tanto pelo indivíduo empreendedor (nível individual) como pela empresa (nível organizacional).

Outro antecedente que pode ser destacado é a percepção dos sinais de uma oportunidade, identificado em 11\% das ocorrências. Em todas as ocorrências para essa categoria observou-se o nível de análise individual, ou seja, a percepção tem origem no indivíduo empreendedor. Em termos de nível de análise, portanto, os resultados obtidos reforçam a constatação da análise da literatura internacional a respeito do foco das perspectivas teóricas em processos de oportunidades no nível individual de análise e na ênfase que se confere ao indivíduo empreendedor em detrimento de outras formas coletivas de empreendedorismo.

ALBANAZ, F.; MATITZ, Q. R. S. Uso do conceito oportunidade em livros nacionais de empreendedorismo à luz da literatura científica da área. Revista de Empreendedorismo e Gestão de Pequenas Empresas, v.5, n.2, 2016. 
QUADRO 2 - ELEMENTOS E/OU PROCESSOS ANTECEDENTES DA OPORTUNIDADE EMPREENDEDORA IDENTIFICADOS NOS LIVROS QUE COMPÕEM O CORPUS DA PESQUISA

\begin{tabular}{|l|c|}
\hline \multicolumn{1}{|c|}{ ANTECEDENTES } & QUANTIDADE \\
\hline $\begin{array}{l}\text { Fatores individuais: capacidade de observação, percepção, conhecimento } \\
\text { anterior, criatividade, competência, coragem, desejo, informação privilegiada, } \\
\text { hobby relacionado ao negócio, espírito empreendedor, acesso a fonte de } \\
\text { informação, problema pessoal }\end{array}$ & 87 ocorrências \\
\hline $\begin{array}{l}\text { Fatores organizacionais: [ferramentas ou capacidade de] análise da da } \\
\text { concorrência, análise do comportamento do consumidor, análise do ambiente } \\
\text { interno e externo; crescimento do negócio; mudança/ampliação de objetivos, } \\
\text { uso de tecnologia da informação }\end{array}$ & 16 ocorrências \\
\hline $\begin{array}{l}\text { Fatores ambientais: oportunidades, ameaças, características do ambiente } \\
\text { de negócios, tendências econômicas e sociais, grandes eventos, situação de } \\
\text { risco que origina oportunidades }\end{array}$ & 26 ocorrências \\
\hline TOTAL & $\mathbf{1 2 9}$ ocorrências \\
\hline
\end{tabular}

FONTE: Os autores (2016).

Em relação aos outcomes (resultados), foram identificadas e classificadas 113 ocorrências. Conforme descrito no quadro abaixo, pode-se observar que a maioria dos tipos de outcomes encontrados estão diretamente relacionados com o indivíduo empreendedor, tais como: ultrapassar os limites pessoais/profissionais; abrir um novo negócio; sentimento de realização e satisfação pessoal.

Em menor número, podem-se observar tipos de outcomes relacionados ao novo negócio/empreendimento, tais como: posse de novo espaço competitivo; adequação do produto ou serviço ao consumidor; oferta de novos produtos/serviços; mudanças nos rumos da empresa; diferencial competitivo; conquistar espaço competitivo.

É importante destacar ainda que, apesar de haver mais tipos de categorias relacionadas à empresa, em termos de quantidade absoluta há mais ocorrências relacionadas ao indivíduo empreendedor. 
QUADRO 3 - ELEMENTOS E/OU PROCESSOS CONSEQUENTES DA OPORTUNIDADE EMPREENDEDORA IDENTIFICADOS NOS LIVROS QUE COMPÕEM O CORPUS DA PESQUISA

\begin{tabular}{|l|r|}
\hline \multicolumn{1}{|c|}{ CONSEQUENTES } & QUANTIDADE \\
\hline $\begin{array}{l}\text { Fatores individuais: abrir um novo negócio, ultrapassar os limites } \\
\text { pessoais/profissionais, sentimento de realização; ter alternativa de fonte de } \\
\text { renda, satisfação pessoal, realizar projetos }\end{array}$ & 93 ocorrências \\
\hline $\begin{array}{l}\text { Fatores organizacionais: posse de novo espaço competitivo; adequação do } \\
\text { produto ou serviço ao consumidor; oferta de novos produtos/serviços; } \\
\text { mudanças nos rumos da empresa; conquistar diferencial competitivo; } \\
\text { conquistar espaço competitivo; obter sucesso }\end{array}$ & 20 ocorrências \\
\hline TOTAL & $\mathbf{1 1 3}$ ocorrências \\
\hline
\end{tabular}

FONTE: Os autores (2016).

A Figura 2 a seguir demonstra graficamente as principais relações teóricas estabelecidas nos livros de autores brasileiros em relação ao conceito de oportunidade empreendedora.

FIGURA 2 - REPRESENTAÇ̃̃O GRÁFICA DAS RELAÇÕES TEÓRICAS RELACIONADAS AO CONCEITO OPORTUNIDADE EMPREENDEDORA IDENTIFICADAS NOS LIVROS QUE COMPÕEM O CORPUS DA PESQUISA

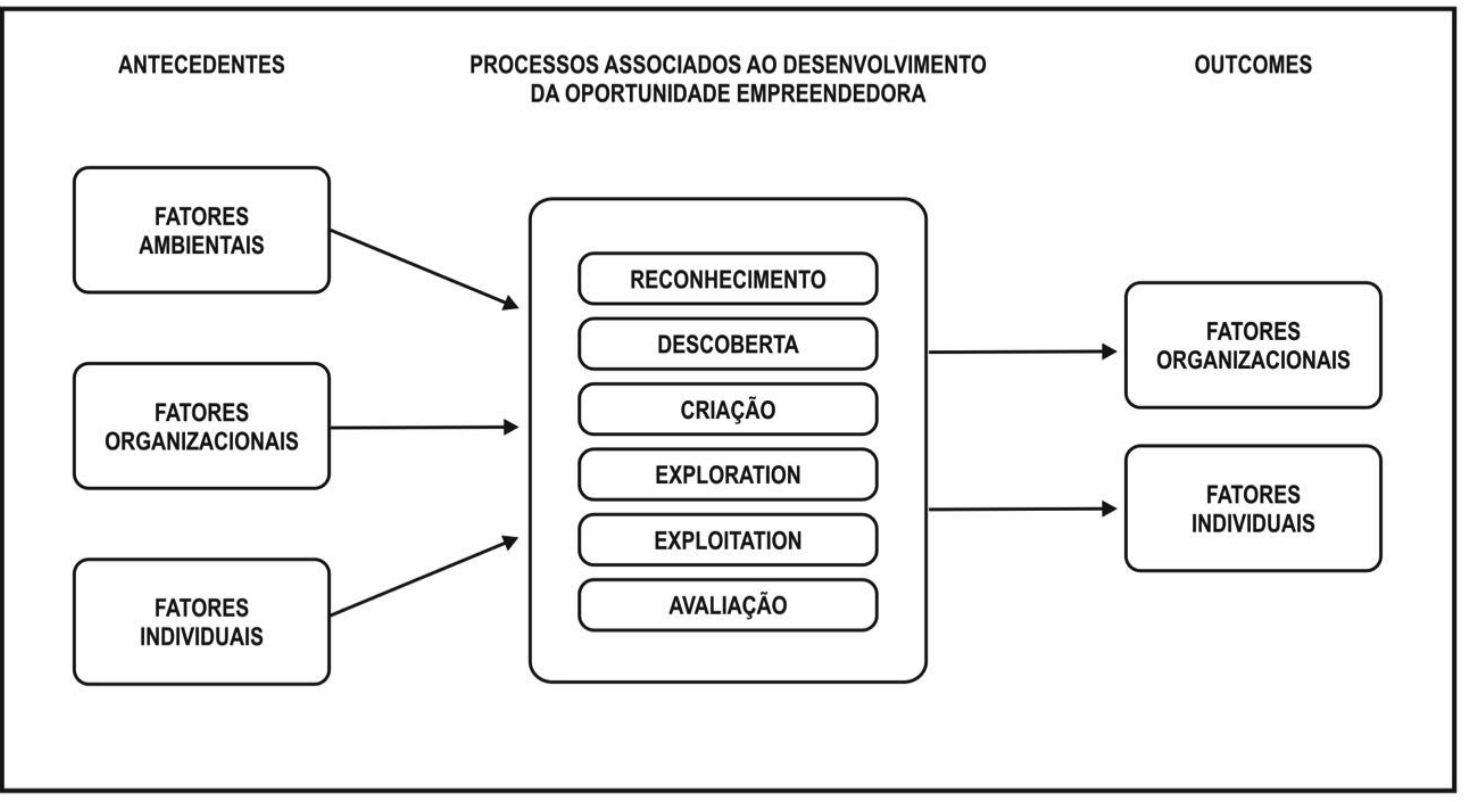

FONTE: Os autores (2016).

Quanto aos antecedentes das oportunidades empreendedoras, os resultados obtidos na análise confirmam as propostas teóricas recentes de estudos científicos de empreendedorismo na medida em que foram identificados aspectos variados relacionados ao indivíduo (cognição, capital social, aprendizagem, comportamento, personalidade, capacidade comercial, acesso a recursos, etc.), à 
organização (capacidades, estratégias, etc.) e ao contexto ambiental (cultura, sociedade, etc.). Não foram identificados antecedentes relacionados ao nível de análise de equipe/grupo.

A análise dos outcomes das oportunidades em livros nacionais de empreendedorismo permitiu observar predominância de resultados diretamente relacionados ao indivíduo empreendedor, com destaque para a abertura de um novo negócio, o enfrentamento de novos desafios e a necessidade de ultrapassar os limites pessoais/profissionais. Em seguida, foram identificadas ocorrências relacionadas aos resultados das oportunidades empreendedoras em nível organizacional, tais como: entrada em novos mercados e obtenção de sucesso.

De acordo com as propostas teóricas recentes de estudos científicos de empreendedorismo, observa-se uma diferença relevante na medida em que ressaltam, além da criação de novos negócios, outros efeitos do desenvolvimento de oportunidades empreendedoras, como geração de riqueza, solução de ineficiências de mercado, inovação, desenvolvimento econômico, dentre outros.

Em síntese, nas obras de autores brasileiros analisadas, observa-se uma ênfase nos efeitos da oportunidade sobre a vida profissional e pessoal do indivíduo empreendedor, enquanto aspectos relacionados à própria organização são menos frequentes e os relacionados ao ambiente mais amplo são ignorados.

A natureza do estilo de escrita das obras analisadas não permitiu a identificação de elementos moderadores das oportunidades empreendedoras, conforme propostos nas teorias da área.

\section{Considerações Finais}

Esta pesquisa teve como principal objetivo estudar como o conceito de oportunidade está sendo apresentado em livros de autores brasileiros voltados à disseminação do empreendedorismo, à luz da literatura científica da área. Por se tratar de uma área de estudos em desenvolvimento, o estudo dos conceitos-chave do empreendedorismo é de grande importância, pois amplia a capacidade de

ALBANAZ, F.; MATITZ, Q. R. S. Uso do conceito oportunidade em livros nacionais de empreendedorismo à luz da literatura científica da área. Revista de Empreendedorismo e Gestão de Pequenas Empresas, v.5, n.2, 2016. 
compreensão dos fenômenos específicos da área e contribui para a criação de novas teorias.

De forma geral, a partir dos resultados obtidos, pode-se inferir que as obras analisadas estão conceitualmente alinhadas à área de estudos de empreendedorismo em âmbito internacional, com exceção das atribuições de outcomes às oportunidades empreendedoras. Ou seja, enquanto a literatura científica da área propõe que os resultados da oportunidade empreendedora abrangem os mercados e a sociedade como um todo, os autores brasileiros dos livros analisados privilegiam os resultados individuais da identificação e desenvolvimento da oportunidade de novos negócios. De igual forma, foi identificada uma diferença na atribuição de antecedentes entre as literaturas analisadas, na medida em que elementos de nível de equipe/grupo não foram identificados nos livros do corpus da pesquisa.

Recomenda-se a realização de trabalhos futuros em amostras ampliadas de publicações nacionais voltadas à disseminação do empreendedorismo. Nesse sentido, sugere-se a realização de estudos empíricos a respeito da aplicação do conceito de oportunidade na prática de empreendedores brasileiros, considerandose as categorias de análise utilizadas nesta investigação. Sob o ponto de vista teórico, podem ser realizados estudos a respeito das contribuições de teorias relacionadas ao conceito de oportunidade para a compreensão do fenômeno no contexto nacional, além de estudos comparativos do significado da oportunidade empreendedora em diferentes tipos de empreendedorismo: social, coletivo, dentre outros.

Por fim, estudiosos do empreendedorismo podem buscar desenvolver modelos teóricos complexos, considerando antecedentes, moderadores, mediadores e outcomes do fenômeno. Dessa forma, espera-se que haja um entendimento crescente e ampliado a respeito da origem das oportunidades de negócios, das interações individuais e organizacionais relacionadas ao processo, além dos diferentes tipos de oportunidades e suas relações com diferentes tipos de negócios e contextos. 


\section{Referências:}

ALDRICH, H. E.; CLIFF, J. E. The pervasive effects of family on entrepreneurship: toward a family embeddedness perspective. Journal of Business Venturing, v. 18, n.5, p. 573-596, 2003.

ALVAREZ, S.; BARNEY, J. B. Discovery and Creation: Alternative Theories of Entrepreneurial Action. Organizações em Contexto, Ano 3, n. 6, 2007.

ARDICHVILI, A.; CARDOZO, R.; RAYC, S. A theory of entrepreneurial opportunity identification and development. Journal of Business Venturing, v. 18, n. 1, p. 105123, 2003.

BARDIN, L. Análise de conteúdo. São Paulo: Edições 70, 2011.

BERNARDES, M. E. B.; MARTINELLI, D. P. Programa de empreendedorismo em instituições de ensino superior: reflexões a partir de algumas experiências canadenses e americanas. Revista de Negócios, v. 9, n. 2, p. 117-126, 2004.

BLUNDELL, R.; LOCKETT, N. Exploring Entrepreneurship: practices and perspectives. Oxford University Press: 2011.

CABRAL, R. M. Estratégias didáticas para o ensino do empreendedorismo em cursos de pós-graduação lato sensu. In: I Encontro de Ensino e Pesquisa em Administração e Contabilidade - EnEPQ, 2007, Recife, Anais... Recife, 2007.

CAROLIS, D. M. de; SAPARITO, P. Social Capital, Cognition, and Entrepreneurial Opportunities: A Theoretical Framework. Entrepreneurship Theory and Practice, v. 30, n. 1, p. 41-56, 2006.

COHEN, B.; WINN, M. Market imperfections, opportunity and sustainable entrepreneurship. Journal of Business Venturing, v. 22, n. ,1 p.29-49, 2007.

DIMOV, D. Beyond the Single-Person, Single-Insight Attribution in Understanding Entrepreneurial Opportunities. Entrepreneurship Theory and Practice, v. 31, n. 5, p. 713-731, 2007.

FLORES, D. C.; HOELTGEBAUM, M.; SILVEIRA, A. O ensino do empreendedorismo nos cursos de pós-graduação em administração no Brasil. Revista de Negócios, v. 13, n. 2, p. 93-104, 2008.

GELLNER, E. A. Conceito. In: SILVA, B. (Coord.). Dicionário de ciências sociais. Rio de Janeiro: Editora da FGV, 1986.

GUTIERREZ, F. Autores lançam livros em série sobre ter um negócio. Folha de São Paulo, São Paulo. 22 dez. 2013. Disponível em: $<$ http://classificados.folha.uol.com.br/negocios/2013/12/1388477-autores-lancamlivros-em-serie-sobre-ter-um-negocio.shtml>. Acesso em: 24 mai. 2014.

ALBANAZ, F.; MATITZ, Q. R. S. Uso do conceito oportunidade em livros nacionais de empreendedorismo à luz da literatura científica da área. Revista de Empreendedorismo e Gestão de Pequenas Empresas, v.5, n.2, 2016. 
HENRIQUE, D. C.; CUNHA, S. K. da. Práticas didático-pedagógicas no ensino de empreendedorismo em cursos de graduação e pós-graduação nacionais e internacionais. RAM - Revista de Administração Mackenzie, v. 9, n. 5, p. 112-136, 2008.

HUNTER, M. A typology of entrepreneurial opportunity. Economics, Management, and Financial Markets, v. 8, n. 2, p. 128-166, 2013.

KIRZNER, I. Competition and Entrepreneurship. Chicago: University of Chicago Press, 1973.

MATITZ, Q. R. S.; VIZEU, F. Construção e uso de conceitos em estudos organizacionais: por uma perspectiva social e histórica. Rev. Adm. Pública [online], v. 46, n. 2, p. 577-598, 2012.

NASSIF, V. M. J.; SILVA, N. B.; ONO, A. T.; BONTEMPO, P. C.; TINOCO, T.. Empreendedorismo: área em evolução? Uma revisão dos estudos e artigos publicados entre 2000 e 2008. RAl - Revista de Administração e Inovação, v. 7, n. 1, p. 142-157, 2010.

SCHINDEHUTTE, M.; MORRIS, M. H. Advancing Strategic Entrepreneurship Research: the role of complexity science in shifting the paradigm. Entrepreneurship Theory and Practice, v. 33, n. 1, p. 241-276, 2009.

SCHUMPETER, J. A. Economic theory and entrepreneurial history. In: WOHL, R. R. Change and the entrepreneur: postulates and the patterns for entrepreneurial history. Cambridge: Harvard University Press, 1949.

SOUZA, A. M. de; SARAIVA, L. A. S. Práticas e desafios do ensino de empreendedorismo na graduação em uma instituição de ensino superior. Gestão \& Regionalidade, v. 26, n. 78, 2010.

SOUZA, E. C. L. de; SOUZA, C. C. L. de; ASSIS, S. de A. G.; ZERBINI, T. Métodos e Técnicas de Ensino e Empreendedorismo em IES Brasileiras. In: XXVIII Encontro da ANPAD, 2004, Curitiba, Anais... Curitiba, 2004.

SHORT, J. C.; KETCHEN JR., David J.; SHOOK, C. L.; IRELAND, R. D. The Concept of "Opportunity" in Entrepreneurship Research: Past Accomplishments and Future Challenges. Journal of Management, v. 36, n. 1, p. 40-65, 2010.

ALBANAZ, F.; MATITZ, Q. R. S. Uso do conceito oportunidade em livros nacionais de empreendedorismo à luz da literatura científica da área. Revista de Empreendedorismo e Gestão de Pequenas Empresas, v.5, n.2, 2016. 